\title{
A New Species of Mictognatbus (Acari: Halacaridae) from the Great Barrier Reef ${ }^{1}$
}

\author{
Fürgen C. Otto ${ }^{2}$
}

\begin{abstract}
Mictognatbus colemani Otto, n. sp., is described from the Great Barrier Reef. It is the third known species in its genus and the first species of Mictognathus known to occur in tropical waters. Distinguishing features are dorsal lamellae on the telofemora, membranous flaps on anterior and posterior dorsal plates, lack of distinct areolae or costae, relatively long median claws on all legs, and the lack of corneae. Some of these characters are similar to those of the mictognathine species Corallibalacarus chilcottensis, but it is unknown whether they indicate a close relationship. A key to species of Mictognatbus is presented.
\end{abstract}

Mites of the family Halacaridae are common but minute $(0.2-2 \mathrm{~mm})$ inhabitants of the marine benthos and occur from the intertidal zone to the abyss. Approximately 1000 species have been described to date, but new species are added frequently, suggesting that many, perhaps most, of the world's halacarid species are still unknown. A genus only rarely encountered during halacarid surveys is Mictognathus Newell, of which two species were known previously, $M$. werthelloides Newell, 1984, and M. secundus Bartsch, 1992. In this paper I describe a third species of Mictognatbus, which was found in coral sand in the southern section of Australia's Great Barrier Reef Marine Park.

\section{MATERIALS AND METHODS}

The holotype specimen, deposited in the Queensland Museum (QM), at the branch Museum of Tropical Queensland in Townsville, was extracted from a hand-collected and subsequently frozen sediment sample. After

\footnotetext{
${ }^{1}$ Funding for this project provided by the Australian Biological Resources Study (ABRS). This publication is AIMS contribution no. 990. Manuscript accepted 25 April 2000.

${ }^{2}$ Australian Institute of Marine Science, PMB 3, Townsville, Queensland 4810, Australia (E-mail: j.otto @aims.gov.au).
}

Pacific Science (2001), vol. 55, no. 1:43-46

(C) 2001 by University of Hawai'i Press

All rights reserved thawing, the sample was vigorously stirred in a bowl of water and the supernatant decanted through a $100-\mu \mathrm{m}$ sieve. The specimen was cleared in lactic acid and mounted in PVA. Measurements and the illustrations were obtained from the slide-mounted, slightly compressed specimen. Abbreviations in the description are as follows: $\mathrm{AD}$, anterior dorsal plate; $\mathrm{AE}$, anterior epimeral plate; GA, genitoanal plate; GO, genital opening; OC, ocular plate; pas, parambulacral seta(e); $\mathrm{PD}$, posterior dorsal plate; $\mathrm{P}-1$ to $\mathrm{P}-4$, palp segments designated in sequence from the proximal to the distal; I-IV, leg I to leg IV. Additional abbreviations used in the illustrations are explained in their captions.

Subfamily Mictognathinae Otto, 1999
Genus Mictognatbus Newell, 1984

Mictognatbus Newell, 1984:211; Bartsch, 1992:85 (type species: Mictognatbus secundus Newell, 1984, by monotypy and original designation).

Mictognathus colemani Otto, n. sp. Figures 1, 2

TYPE MATERIAL: Holotype: male, QMS105562, Great Barrier Reef, Turner Cay, NE, ca. $21^{\circ} 43^{\prime} \mathrm{S}, 152^{\circ} 33^{\prime} \mathrm{E}, 8$ December 1998, G. Coleman coll., sand on reef flat. ETYMOLOGY: Named in honor of Greg Coleman, who collected the only known specimen of this species.

DIAGNosis: Dorsal and ventral plates 


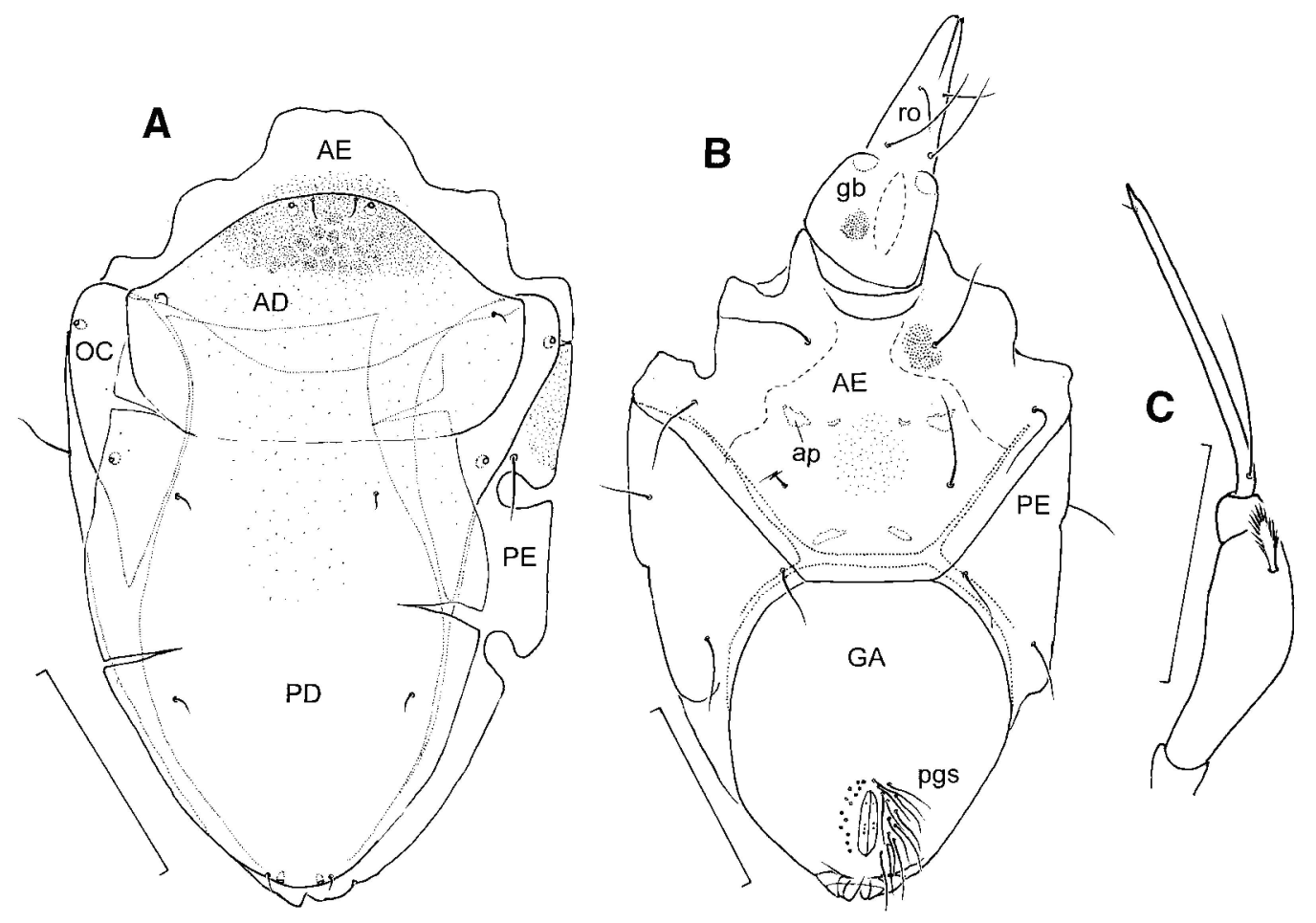

FIGURE 1. Mictognathus colemani, n. sp., male. $A$, Idiosoma, dorsal view; $B$, idiosoma and gnathosoma, ventral view; $C$, palp, dorsal view. $\mathrm{AD}$, anterior dorsal plate; $\mathrm{AE}$, anterior epimeral plate; ap, apodeme; $\mathrm{GA}$, genitoanal plate; gb, gnathosomal base; $\mathrm{OC}$, ocular plate; $\mathrm{PD}$, posterior dorsal plate; $\mathrm{PE}$, posterior epimeral plate; pgs, perigenital setae; ro, rostrum. Scale bars: $A, B, 100 \mu \mathrm{m} ; C, 50 \mu \mathrm{m}$.

overlapping, closely abutting or fused (Figure $1 A, B)$. AE dorsally fused, forming a collar. Anal opening visible in ventral view. Five pairs of dorsal setae (excluding seta on PE). Gnathosomal base about as long as wide. Rostrum triangular, not connected to idiosoma via a flexible neck; both pairs of maxillary setae on rostrum. Palps four-segmented (Figure $1 C$ ), attached laterally; $\mathrm{P}-2$ with one dorsal seta; $\mathrm{P}-3$ with a minute median seta or seta absent; P-4 very slender, at least as long as P-2 and P-3 combined, with a single basal seta. Trochanters III and IV with dorsal triangular process or lamella. Tibiae I-IV with two bipectinate ventral setae. Telofemora I and II with large ventral lamellae. Telofemora, genua, and tibiae with elaborate articular lamellae. Tarsus I with three dorsal setae, one or two eupathid ventral setae, and a pair of doubled pas. Tarsus III with three dorsal setae, one ventral seta, and either a pair of doubled pas or a pair of pas singlets. Tarsi III and IV with three dorsal setae and a pair of pas singlets. Solenidion on tarsus I in dorsomedial position, that on tarsus II dorsolateral. All tarsi with two paired claws and median claw, all without pecten.

DESCRIPTION: Male: Idiosoma $343 \mu \mathrm{m}$ long. $\mathrm{AD}$ posteriorly with very delicate membranous flap that partly covers $\mathrm{PD}$ and OC. Similar delicate flaps, ruptured in several places on the only available specimen, laterally on PD. Dorsal plates in deeper layers more clearly separated and better defined (dotted lines in Figure 1A). AD anteriorly with dense clusters of canaliculi, remainder of dorsum with scattered canaliculi. Dorsal part of $\mathrm{AE}$ finely punctate. $\mathrm{AD}$ with a pair of setae and a pair of pores anteriorly and a second pair of setae near lateral margin. OC with two 


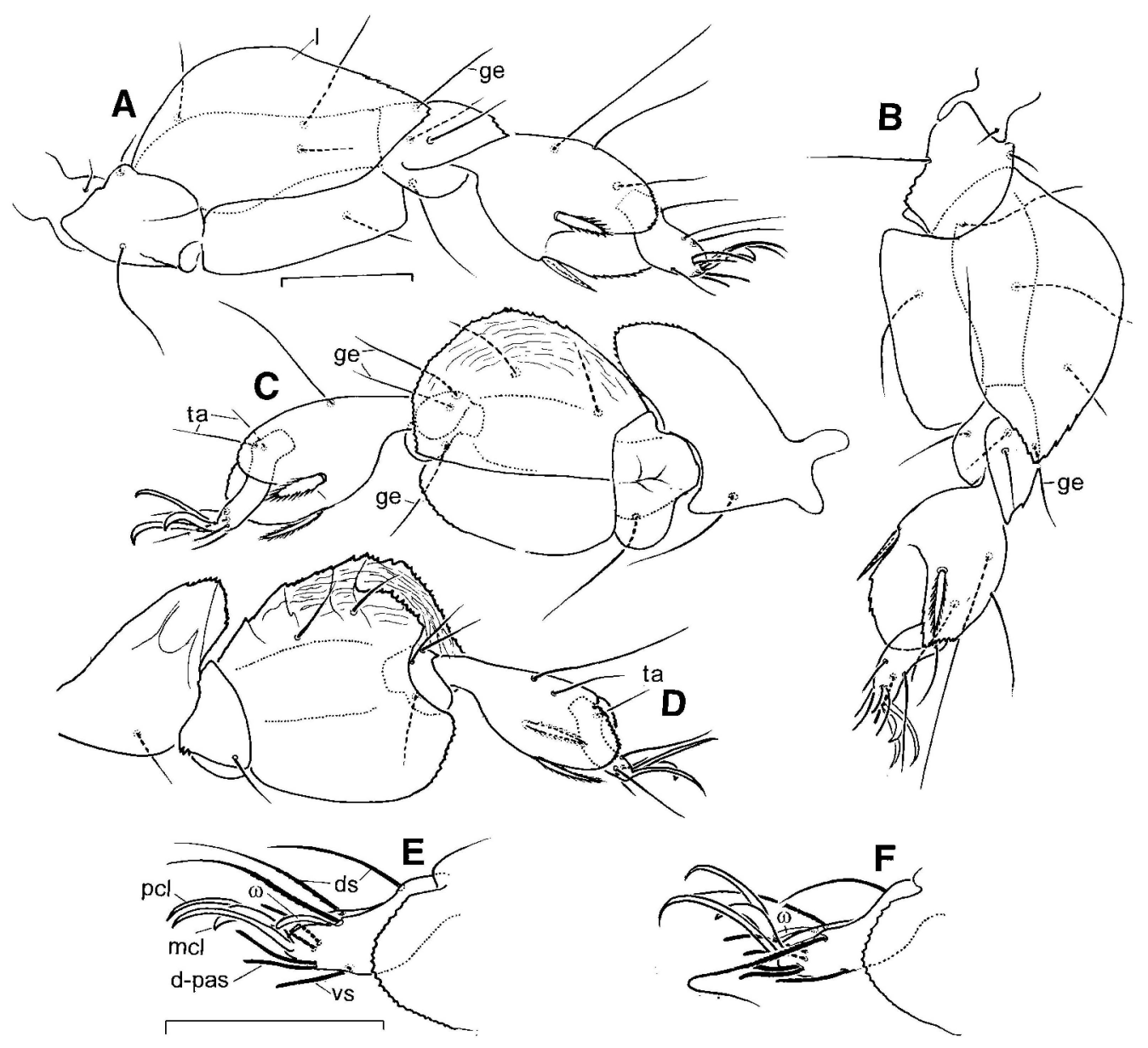

FIGURE 2. Mictognatbus colemani, n. sp., male. $A$, Leg I, medial view; $B$, leg II, medial view; $C$, leg III, medial view; $D$, leg IV, medial view; $E$, tarsus I, lateral view; $F$, tarsus II, lateral view. d-pas, doubled parambulacral seta; ds, dorsal setae on tarsus; ge, seta on genu; 1, lamella; mcl, median claw; pcl, paired claw; ta, seta on tarsus; vs, ventral seta on tarsus; $\omega$, solenidion. Scale bars: $A, E, 50 \mu \mathrm{m} ; B-D$, same scale as $A ; F$, same scale as $E$.

pairs of pores laterally. One pair of setae about halfway along idiosoma, two other pairs of dorsal setae and a pair of gland pores in posterior half of idiosoma. Ventral plates on surface closely abutting, separated on surface only by thin groove, in deeper layers more clearly separated (dotted line in Figure $1 B$ ). $\mathrm{AE}$ on either side densely punctate, medially with more scattered canaliculi and several apodemes. GO surrounded by 26 perigenital setae; several minute setal insertions but no setae seen on GO.

Gnathosomal base densely punctate except for a smooth area overlying the pharyngeal plate. Rostrum slightly longer than gnathosomal base. Segment P-2 with a plumose dorsal seta (Figure $1 C$ ), P-3 without seta.

Telofemora of all legs with elaborate dorsal and ventral lamellae, those on I and II appearing smooth, those on III ornamented as illustrated (Figure 2C,D). Chaetotaxy (trochanter-tibia): I 1-2-4-4-5 (Figure 2A), II 1-2-4-4-5 (Figure 2B), III 1-1-2-3-3 (Figure 2C), IV 1-1-2-3-4 (Figure 2D), several setae on the genua obscured by lamellae. Tarsi I and II with three dorsal setae (the distal pair 
serrated), unpaired ventral seta, and pair of doubled pas (Figure 2E,F). Tarsi III and IV with three dorsal setae and a pair of pas singlets. Median claw of all legs longer than half the length of paired claws.

Female: Unknown.

REMARKs: Mictognathus colemani, n. sp., differs from its congeners, $M$. werthelloides Newell and M. secundus Bartsch, by the presence of dorsal lamellae on the telofemora, the median claw being longer than half the length of the paired claws, the lack of corneae, the lack of distinct areolae or costae on the dorsal plates, and the presence of membranous flaps on the $\mathrm{AD}$ and PD.

The relatively long median claws, the dorsal lamellae on the telofemora, and the lack of corneae are all similar to characters of the mictognathine species Corallibalacarus chilcottensis Otto, 1999. However, whether they indicate a close relationship of $M$. colemani and C. chilcottensis or are the result of convergent evolution is unknown.

Mictognatbus was previously recorded only from antarctic or subantarctic waters: $M$. secundus from Tierra del Fuego (Bartsch 1992) and $M$. werthelloides from off the South Sandwich Islands (Bartsch 1992), Palmer Peninsula (Newell 1984, Bartsch 1992), and Commonwealth Bay (Newell 1984, questioned by Bartsch 1992). The discovery of a tropical Mictognathus species shows that Mictognathus is not confined to cold water habitats.

\section{KEY TO SPECIES OF Mictognathus}

1. $\mathrm{AD}, \mathrm{OC}$, and $\mathrm{PD}$ with areolae or costae consisting of rosette pores; telofemora with ventral but without dorsal lamella; median claw on tarsi shorter than half the

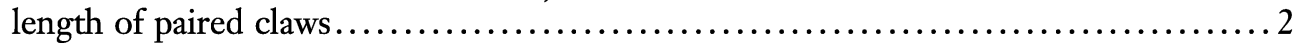

Idiosoma anteriorly densely covered with canaliculi, remainder of dorsum with scattered canaliculi (Figure $1 A$ ), rosette pores and costae absent; telofemora with ventral and dorsal lamella (Figure $2 A-D$ ); median claw on tarsi longer than half the length of

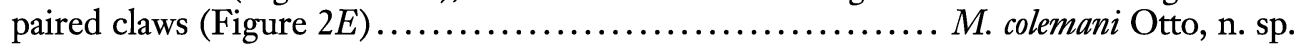

2. Ventral plates completely fused; seta on P-2 broad and plumose; OC with two gland pores M. secundus Bartsch

Ventral plates contiguous but not fused; seta on P-2 fine, glabrous, and tapering; OC with one gland pore. M. werthelloides Newell

\section{ACKNOWLEDGMENTS}

I thank the Australian Biological Resources Study (ABRS) for funding this project and the Australian Institute of Marine Science (AIMS) for providing laboratory and office space. I am indebted to Greg Coleman and the AIMS long-term monitoring group, who provided the sample from which the new species was extracted. The Great Barrier Reef Marine Park Authority (GBRMPA) kindly gave permission to collect mites within the boundaries of the marine park.

\section{Literature Cited}

Bartsch, I. 1992. Mictognathus secundus, a psammophilous halacarid mite (Acari: $\mathrm{Ha}-$ lacaridae). Acarologia 33:85-89.

Newell, I. M. 1984. Antarctic Halacaroidea. Antarct. Res. Ser. 40:1-284.

Otto, J. C. 1999. Corallibalacarus chilcottensis, a new genus and species of marine mite from the Coral Sea (Acari: Halacaridae). Zool. Sci. 16:839-843. 